\title{
Altas habilidades: UMA QUeSTÃo escolaR ${ }^{1}$ GIFTEDNESS: A SHOOL MATTER
}

\author{
Célia Maria Paz Ferreira BARRETO² \\ Marsyl Bulkool METTRAU ${ }^{3}$
}

\begin{abstract}
RESUMO: esse estudo foi realizado em uma escola federal de ensino, localizada no Rio de Janeiro. Estabeleceu como objetivos gerais investigar as representações dos professores sobre as altas habilidades e a existência da indicação de alunos com esse perfil para atendimento. Utilizou duas amostras diferenciadas. A primeira, formada por 36 professores que atuavam do $1^{\circ}$ ao $9^{\circ}$ ano do ensino fundamental e do $1^{\circ}$ ao $3^{\circ}$ ano do ensino médio. A outra amostra foi constituída por quatro setores da escola responsáveis pelo registro histórico dos alunos. Utilizou-se a metodologia da análise de conteúdo no tratamento dos dados obtidos. Os resultados mostraram que os professores respondentes têm representações sobre altas habilidades e que não existem alunos com altas habilidades matriculados na instituição. Os resultados indicam urgência no implemento de ações inclusivas para as altas habilidades nessa escola, assim como a continuidade e aprofundamento nessa pesquisa.
\end{abstract}

PALAVRAS-CHAVE: Educação Especial. Altas Habilidades. Representações. Atendimento.

\begin{abstract}
The study took place in a public federal school in Rio de Janeiro. The overall objectives were to investigate representations teachers have about giftedness and existing indications of such students that should be referred to specific learning and counseling programs. Two different groups were taken as samples. The first was made up of 36 elementary and high school teachers. The other consisted of four school sectors, charged with keeping students data records. The qualitative method of contents analysis was used. This study indicates its participants have representations about giftedness, although there were no gifted students enrolled in the institution where the study took place. The results also suggest that there is a pressing need to implement inclusive actions for gifted students at this school, as well as further developing the investigation at a deeper level.
\end{abstract}

KEYWORDS: Special Education. Giftedness. Representation. Counseling.

\section{INTRODUÇÃo}

As pessoas com altas habilidades/superdotação são, geralmente, "indivíduos criativos e produtivos" (RENZULLI, 2004). Possuem características marcantes, socialmente reconhecidas, no que concerne a um "trabalho original, impregnado pelo novo e configurado pelo inédito" (FAZENDA, 1995). Destacamse em diferentes "áreas do saber e do fazer social" e estão presentes em qualquer população em um percentual que gira em torno de 1\% a 10\% (METTRAU 2000). Podem apresentar "desempenho notável, elevada potencialidade na capacidade intelectual geral, aptidão acadêmica específica, liderança, pensamento criador ou

\footnotetext{
1 Artigo derivado de dissertação de mestrado apresentada ao Programa de Pós-Graduação Stricto Sensu em Psicologia Social, da Universidade Salgado de Oliveira / UNIVERSO como parte dos requisitos para obtenção do título de Mestre em Psicologia.

2 Professora do Colégio Pedro II. Unidade São Cristóvão I. Rio de Janeiro. Brasil. celiapaz13@gmail.com

${ }^{3}$ Professora titular da Universidade Salgado Oliveira. Niterói. Brasil. E-Mail: marsyl@superig.com.br
} 
produtivo, capacidade psicomotora e talento especial para as artes" (MEC 2006). Estes são alguns dos indicadores de destaque que podem se apresentar de forma isolada ou combinados.

As pesquisas sobre este tema tão complexo, polêmico e controverso têm indicado a necessidade de um atendimento especializado para esses sujeitos o mais precocemente possível, preferencialmente dentro das instituições educacionais ao longo da educação básica, porque considera que esse é o lugar e o tempo ideal para o desenvolvimento das suas potencialidades.

Considerando-se a fundamentação supra, buscou-se direcionar essa investigação a partir da detecção da problemática atual da não-indicação e do nãoatendimento aos estudantes com esse perfil nas escolas brasileiras, em sua maioria.

Esse marco determinou a escolha do âmbito escolar para a implementação dessa sondagem, uma vez que o processo de identificação e indicação de alunos com esse perfil às diferentes modalidades de programas de atendimento, está intrinsecamente inserido no trabalho docente dentro das escolas.

Dessa forma definiu-se também a instituição optando-se por uma escola que integra a rede federal de ensino localizada no Rio de Janeiro. Esta atende alunos do ensino fundamental e médio em sua totalidade.

Decidiu-se ainda a constituição de duas amostras. A primeira foi constituída por professores porque a identificação e a indicação dependem do conhecimento desses profissionais sobre o tema e da sua observação sobre esses alunos. A segunda amostra foi composta pelos quatro Setores dessa mesma instituição, responsáveis pelo registro histórico dos alunos, em geral: os 3 Setores de Supervisão e Orientação Pedagógica (SESOP), e o Setor de Educação Especial (SEE). Este último tem a função de atender e desenvolver ações direcionadas às pessoas com necessidades educativas especiais (NEE), neste caso em particular, também para os alunos com altas habilidades / superdotação.

Nessa pesquisa estabeleceram-se dois objetivos gerais: investigar as representações dos professores sobre as altas habilidades e a existência de alunos com esse perfil, indicados para atendimento nessa escola. Além disso, houve a necessidade de se esclarecer algumas questões intrínsecas levando ao estabelecimento de objetivos específicos. Estes buscaram sondar o nível de conhecimento dos participantes sobre a legislação vigente em relação ao tema, o implemento de políticas públicas para atender esses alunos diferenciadamente conforme proposto na lei LDB No 9 394/76 e ainda, a opinião dos docentes sobre o seu papel na indicação e atendimento de tais alunos.

A relevância desse estudo justifica-se e respalda-se na Lei de Diretrizes e Bases da Educação Nacional No 9.394/96, que em seu capítulo V. Da Educação Especial, propõe um ensino diferenciado, preferencialmente, na rede regular de ensino para esses alunos e estabelece diretrizes prevendo possibilidades educativas 
a serem desenvolvidas por professores especializados e capacitados dentro das escolas.

Para efetivação das propostas legais, há que se ressaltar o respaldo do referencial teórico dos especialistas que labutam atualmente nessa área, como Renzulli (citado em BENITO MATE, 1994, p.41-78; RENZULLI, 2004), Mettrau (2000) e Landau (2002). Suas ideias convergem quando apontam a importância da opinião e do juízo do professor na identificação e indicação dos estudantes altamente capazes para os programas específicos de atendimento. Relatam em suas pesquisas resultados semelhantes quanto a superficialidade do conhecimento desses profissionais, nessa área específica e complexa. Segundo eles, esse déficit, vem prejudicand o em muito, a implementação das ações previstas e regulamentadas na legislação, principalmente nas instituições de ensino.

Os autores citam ainda outro quesito bastante relevante que é a necessidade de uma orientação sistematizada das potencialidades dessas crianças o mais precocemente possível.

A partir das suas pesquisas, esses estudiosos desenvolveram concepções de ordem teórico-prática para explicar aspectos referentes às altas habilidades e que foram consideradas e explanadas nesse trabalho em particular.

Érica Landau (2002) utiliza o termo superdotado e propõe um sistema Interativo de Superdotação entre o mundo interior da criança e o ambiente que desafia e estimula as habilidades: inteligência, criatividade e talentos. A autora esclarece que o estímulo emocional deve ser oferecido pelo ambiente visando o fortalecimento do seu ego transmitindo-lhe a coragem para valer-se dos seus talentos. Em sua concepção, enquanto o estímulo intelectual proporciona a informação, o significado e o preparo para os desafios, o ambiente fornece a motivação para a concretização de toda a sua potencialidade. (Fig.1).

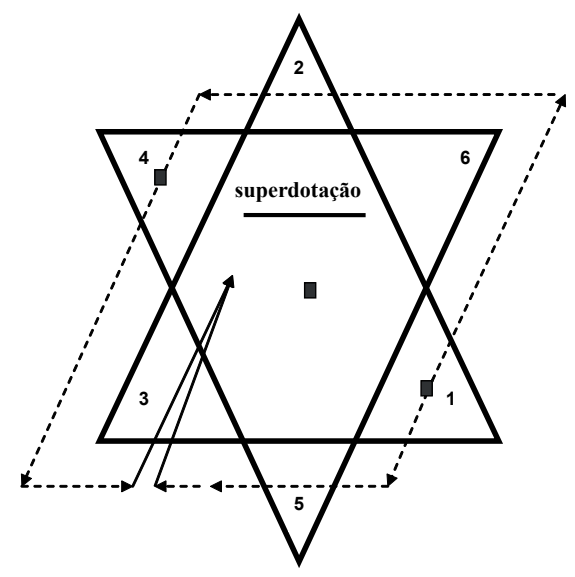

Figura 1 - Sistema Interativo de Superdotação.

Fonte: LANDAU, 2002. 
Joseph Renzulli (1978) concebeu o Modelo dos Três Anéis, posteriormente modificado e denominado Modelo Triádico da Superdotação por Mönks (1992) conforme apresentado em Benito Mate (1996, p.51) e em Barreto e Mettrau (2007, p. 141), para ilustrar as propriedades do movimento, a interação, a mudança e a energia contínuas, inerentes aos grupos de características que o compõem.

O modelo apresenta um conjunto bem definido de três grupos de características entrelaçadas que marcam o perfil dessas pessoas, em particular. São eles: a criatividade, o compromisso com a tarefa e uma habilidade acima da média.

Renzulli enfatiza que um único grupamento de traços, não determina a superdotação, pois esta estaria representada apenas na interseção dos três grupos. Define a criatividade como a originalidade de pensamento, um gênio construtivo, uma habilidade para deixar de lado convenções e procedimentos estabelecidos em detrimento de ideias originais.

Propõe como compromisso com a tarefa um refinamento e uma maneira centrada de motivação, concebida como um processo energizante elevado para resolver problemas, perseverança, resistência, trabalho duro, dedicação, confiança e crença em si para realizar projetos importantes, percepção de um maior sentido para identificar problemas e soluções.

Apresenta a habilidade acima da média sob duas formas organizadas para representar modos peculiares com os quais os sujeitos se expressam em problemas reais. São elas: a habilidade geral que se refere à capacidade para processar informação, integrar experiências vividas para chegar a um resultado novo, buscar respostas apropriadas com vista a adaptação à novas situações e gerar pensamento abstrato. E a habilidade específica a qual visa adquirir conhecimentos padrões e realizar atividades de um tipo especializado dentro de uma gama restrita. (Fig.2).

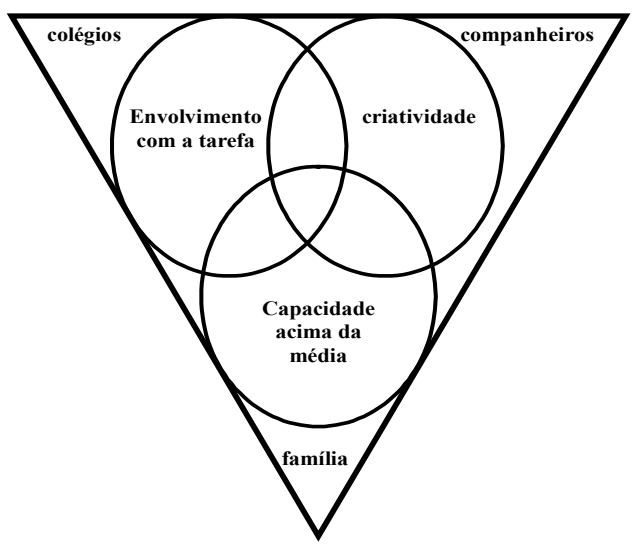

Figura 2 - Modelo Triádico de Superdotação,

Fonte: BENITO MATE, 1996. 
Mettrau (2007) idealizou o Diagrama do Funcionamento da Inteligência Humana com o intuito de representar o movimento contínuo e integrado das expressões cognitiva, afetiva e criativa. Ela explica que tais expressões são distintas, mas mantêm-se permanentemente indissociáveis em um desenvolvimento harmônico, dentro do grupo social.(Fig. 3).

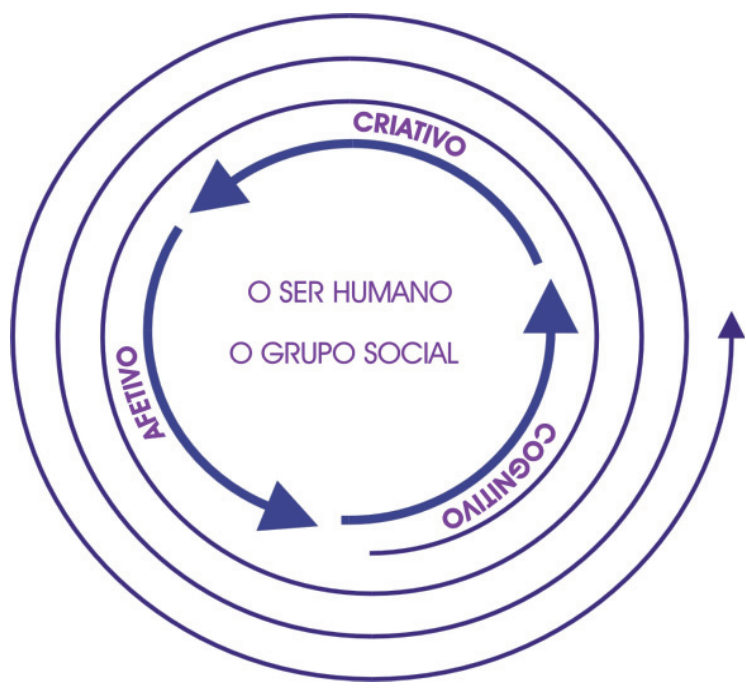

Figura 3 - Diagrama do Funcionamento da Inteligência Humana. Fonte: METTRAU, 2007.

Torna-se fundamental esclarecer que as diferentes investigações sobre o tema concordam no sentido de que não se pode adotar apenas um único critério na determinação das altas habilidades / superdotação, uma vez que se trata de um processo complexo, com múltiplos vieses a serem observados.

\section{MÉTodo}

\subsection{Participantes}

Esse inquérito instituiu a formação de dois tipos de amostras. A primeira do tipo "probabilística, aleatória" (RICHARDSON, 2008) foi formada por 36 professores: 15 oriundos do primeiro segmento do ensino fundamental (do $1^{\circ}$ ao $5^{\circ}$ ano escolares / Unidade I), 12 do segundo segmento do ensino fundamental (do $6^{\circ}$ ao $9^{\circ}$ ano escolares/ Unidade II) e 9 do ensino médio (do $1^{\circ}$ ao $3^{\circ}$ ano escolares / Unidade III). A segunda amostra foi do tipo "não probabilística intencional" (RICHARDSON, 2008), composta dos três Setores de Supervisão e Orientação Pedagógica (SESOP) da escola, responsáveis pelo registro histórico dos alunos e pelo Setor de Educação Especial (SEE) que se ocupa de todos os alunos com necessidades educativas especiais. 
Torna-se necessário esclarecer a utilização do termo Unidade no decorrer do cômputo dos dados. Esta nomenclatura é a utilizada por essa escola onde se realizou a pesquisa na organização do espaço onde funciona cada um dos segmentos da Educação Básica: Unidade I, professores do $1^{\circ}$ ao $5^{\circ}$ anos escolares e Unidade II, professores do $6^{\circ}$ ao $9^{\circ}$ anos escolares do ensino fundamental. Unidade III, professores do $1^{\circ}$ ao $3^{\circ}$ anos escolares do ensino médio.

\subsection{INSTRUMENTOS}

Construiu-se um conjunto composto por três questionários diferentes. $\mathrm{O}$ primeiro direcionado aos professores. O segundo para os três SESOPs e o terceiro para o SEE.

\subsection{Procedimento}

Em um período anterior à realização da pesquisa propriamente dita, introduziu-se o tema nessa escola, por ocasião de um encontro de formação continuada para os professores do primeiro segmento do ensino fundamental (do $1^{\circ}$ ao $5^{\circ}$ anos escolares). Os objetivos da palestra ministrada foi informar e refletir sobre as questões inerentes às altas habilidades/ superdotação. Buscou-se também observar o nível de informação desses profissionais sobre o tema. Foi evidente o interesse do grupo que manifestou-se através das perguntas, trocas interpessoais, reflexões pessoais e relatos de vivências profissionais com esses alunos. Tal curiosidade estendeu-se ao longo do período de realização dessa investigação.

Decidiu-se a constituição da amostra dos docentes, a partir da distribuição randômica dos questionários para os professores das diversas disciplinas componentes da grade curricular de cada ano escolar da instituição. Os demais questionários foram entregues diretamente para os responsáveis de cada um dos três SESOPs e para o SEE.

Com relação aos três modelos de questionários, há que se esclarecer que estes foram estruturados com questões fechadas (Sim ou Não), além das questões fechadas (Sim ou Não) com detalhamento e questões abertas objetivas. Para as questões fechadas do tipo nominal e as questões abertas objetivas aplicou-se a "operação básica da contagem do número de casos, anotando-se suas frequências" (RICHARDSON, 2008). Nas questões fechadas com detalhamento manteve-se o mesmo procedimento anterior para os itens Sim e Não e nas justificativas ou detalhamento utilizou-se a análise do conteúdo segundo Bardin (2007). Nesse momento buscou-se depreender os "processos de elaboração e consolidação do sistema de pensamento que sustentam as práticas sociais" (JODELET, 1984) citado por Spink (1993) dos professores dessa escola em relação às altas habilidades/superdotação. 
Cabe ainda informar que os três questionários utilizados são inéditos pois foram construídos especialmente para esse estudo em particular. A proposta foi captar as informações em amplitudes mais abrangentes da seguinte maneira: os professores observam ocorrências no cotidiano com os seus alunos; os SESOPs obtêm informações dos professores, dos próprios alunos e das famílias em cada Unidade Escolar, através de entrevistas e contatos diretos. OSEE recebe informações de todas as Unidades Escolares pelo contato direto com os professores, SESOPs, diretores, com os próprios alunos e famílias, quando necessário. Ao final do cômputo, cruzou-se os dados analisando-se os resultados.

\section{Resultados}

\subsection{Resultados ObTIDOS A PARTIR DOS QUESTIONÁRIOS DIRECIONADOS AOS PROFESSORES}

Com relação ao nível de formação dos docentes, o perfil da amostra composta pelos 36 professores ficou assim caracterizada: quatro professores com nível superior concluído, dois cursando a especialização, quatorze com especialização concluída, quatro cursando o mestrado, sete com o mestrado concluído, dois cursando o doutorado e três com o doutorado concluído.

O resultado, a partir das perguntas que versavam sobre o conceito e a caracterização das altas habilidades, demonstrou que 100\% dos participantes ouviram falar em altas habilidades (pergunta 1), 75\% já perceberam esses alunos em algum momento de sua trajetória profissional (pergunta 2), mas apenas 50\% afirmaram tê-los tido em sua classe (pergunta 4). Detalharam como características principais os indicadores que determinam a capacidade acima da média em atividades especificamente acadêmicas, em sua maioria.

Em relação ao tema políticas públicas e amparo legal, verificou-se que apenas $63 \%$ dos respondentes possuíam informações sobre a existência do amparo legal para o atendimento específico dessa clientela (pergunta 3). A respeito da opinião desses sobre a importância de indicar e atender esse alunado, 94\% optaram pelo Sim (pergunta 7 e 8 ).

No quesito que abordava o papel do professor e a necessidade de formação continuada para esses profissionais, 19\% dos docentes declararam saber lidar com esses alunos (pergunta 5), 28\% já comunicaram aos SESOPs a existência deles em classe (pergunta 6), 89\% reconheceram ser o professor o mais qualificado dos profissionais dentro da escola, para indicar e lidar com eles (pergunta 9) e 100\% do grupo pesquisado desejou ter mais acesso à informações sobre o tema (pergunta 12).

A abordagem sobre a implantação de programas de atendimento específico para alunos com altas habilidades nessa escola apurou que $67 \%$ dos participantes pensaram ser possível implantar essa modalidade de trabalho na instituição (pergunta 10) e 75\% consideraram ser esta uma responsabilidade e atribuição específica do SEE (pergunta 11). 
3.2 Resultados obTidos a PARTIR dos QUESTIONÁRIOS DIRECIONADOS PARA OS TRÊS Setores de Supervisão e Orientação Pedagógica (SESOPs) e o Setor de Educação ESPECIAL (SEE)

Os resultados obtidos a partir da questão que sondava a existência de alunos com altas habilidades nos três segmentos das três Unidades pesquisadas, demonstraram que houve unanimidade para a opção Não (pergunta 1) com os seguintes detalhamentos: "Não há casos confirmados, há apenas suspeitas". "Há indicadores mas não há continuidade nesta investigação". "Há orientação aos pais".

Quanto ao conhecimento da legislação, afirmaram conhecer o amparo legal para atendimento diferenciado a esse alunado (pergunta 5) com apenas uma justificativa: "Conheço a legislação educacional".

Os Setores divergiram em relação a possibilidade de implantação desta modalidade de atendimento na escola (pergunta 6) da seguinte maneira: "a escola possui uma infraestrutura que pode ser adequada, bem como um corpo docente qualificado". "Eu vejo aqui o Laboratório de Aprendizagem que poderia ser uma sala de recursos. Temos professores com formação em psicopedagogia e áreas afins que poderiam estar a frente desses programas". "Embora considere fundamental o atendimento diferenciado independente da legislação por considerá-la inerente à democratização do ensino, tal proposta requer a participação de profissionais com qualificação ou pelo menos orientação para tal".

Houve convergência para a alternativa Sim sobre a pertinência e responsabilidade do SEE nessa tarefa (pergunta 7). Observando-se os detalhamentos: "Acho que no momento da implantação sim, mas posteriormente deveria se generalizar". "Sim, principalmente porque assim está previsto na LDB". "Não considero somente para a Educação Especial, pois tal atendimento é responsabilidade de todos que trabalham na Educação". "Sim, porque são pessoas capacitadas nessa área".

As perguntas totalmente abertas permitiram a transcrição na íntegra das respostas dadas, por serem objetivas e diretas. Cuidou-se para o uso de um critério descritivo das mesmas. Nessa modalidade incluiu-se as pergunta 2, 3 e 4 .

A pergunta 2 questionava se a indicação desses alunos deveria ser efetivada pelos professores. Houve unanimidade afirmativa com o detalhamento. "E também por profissionais que já trabalharam com o aluno antes de ingressar nessa escola".

Inquiriu-se sobre quais capacidades ou destaques haviam sido observadas nos alunos indicados, na pergunta 3. Explicaram da seguinte forma: “Um destaque apenas, uma maior habilidade em determinada área".

Finalmente a pergunta 4 sondou o desenvolvimento de algum tipo de ação para atendimento dessa clientela no momento. Observou-se unanimidade para a opção Não. 


\section{Discussão}

Após o cruzamento dos resultados dos três instrumentos ficou evidenciado que a totalidade dos respondentes já ouviu falar sobre as altas habilidades/ superdotação. Eles explicaram que o seu conhecimento sobre o tema formou-se através de informações obtidas na mídia em geral, em trocas interpessoais informais e formais no âmbito profissional (reuniões pedagógicas, conselhos de classe, histórico de alunos, SESOPs) e Internet. Foi declarado ainda uma experiência de vivência familiar. E apenas dois professores relataram ter recebido conhecimento sistematizado na graduação, em encontros de formação continuada e capacitação.

Nos detalhamentos houve ocorrência de descrições com características de cunho predominantemente acadêmico, notadamente para a capacidade cognitiva acima da média quase sempre relacionadas às atividades escolares acadêmicas. Não houve um índice significativo para os aspectos dirigidos à criatividade e envolvimento com a tarefa, que são características componentes do referido Modelo Triádico de Superdotação (BENITO MATE, 1996). Não foram mencionados também os quesitos elencados na literatura especializada como: a sociabilidade, a afetividade, a coragem, a liderança (LANDAU, 2002) e também as dificuldades em áreas de desenvolvimento (relacionamento, conduta, dentre outros).

Em suas respostas, os participantes demonstraram insegurança e dúvida quanto ao uso dos diferentes conceitos aplicados pela literatura especializada e citaram termos utilizados no cotidiano indiscriminadamente como: talentoso, esforçado, com altas habilidades, superdotado, inteligente.

Os participantes fizeram referência aos mitos que circulam nos diversos âmbitos da sociedade acerca desses sujeitos os quais foram apresentados e analisados por Winner (1998). A dificuldade supracitada ficou evidente quando os docentes detalharam "que observam em sala de aula alunos com certas características acima da média, mas que apenas comentam entre si ou mesmo nos Setores responsáveis", evitando registrá-lo oficialmente.

Esse estudo possibilitou, também inferir que os professores inquiridos admitem possuir um conhecimento superficial sobre as altas habilidades, dado este que vem corroborar com os pesquisadores referenciados nesse trabalho. Esta constatação aponta para a necessidade de um investimento imediato por parte da instituição pesquisada, em subsidiar seus professores com mais informações de forma a assegurar que os mesmos tenham mais embasamento para notar, indicar e lidar com estes alunos. Além disso, atenderia à solicitação bastante significativa $(100 \%)$ dos respondentes que têm interesse em conhecer e aprofundar mais o tema.

Quanto aos resultados referentes aos três Setores de Supervisão e Orientação Pedagógica (SESOP) e o Setor de Educação Especial (SEE) houve unanimidade quanto à inexistência de registro de alunos com altas habilidades na escola. 
Essa informação remete a um paradoxo importante dentro desses Setores, uma vez que relataram haver recebido alunos oriundos de outras instituições com a indicação de altas habilidades em seus históricos. As indicações a que se referiram teriam sido efetivadas " por instituições, professores e outros profissionais que lidaram com os alunos antes do ingresso deles nessa escola". Além disso, acrescentaram-se os detalhamentos de que "não houve continuidade no processo de investigação" por essa escola, que os considerou" apenas casos ainda não confirmados, somente suspeitas de apresentarem tais indicadores" deixando de cumprir uma orientação legal.

Outro contraponto claro que se pode trazer à discussão é a afirmação de que há um conhecimento da legislação com relação ao direito assegurado para essa clientela de um atendimento específico. No entanto, houve unanimidade nas respostas, de que até aquele momento não estavam sendo desenvolvidas ações, nem tampouco, havia previsão de implantação de programas em virtude de não terem uma equipe qualificada. Também chamou a atenção outro relato dos Setores, o de que se faz orientação às famílias desses alunos quanto à possibilidade de seus filhos possuírem altas habilidades, sem contudo, detalharem a natureza desse trabalho.

Concluindo, ficou evidenciado nesse estudo que os professores participantes, os três Setores de Supervisão e Orientação Pedagógica (SESOPs) e o Setor de Educação Especial (SEE) já ouviram falar sobre as altas habilidades, ainda que de forma superficial.

O cruzamento dos dados coletados pelo conjunto dos três questionários aplicados (professores, SESOPs e SEE) permitiu constatar também contradições entre as respostas dos docentes e dos Setores em relação ao objetivo que sondava a existência de registros de indicação dos alunos com altas habilidades,. Embora, oficialmente, a escola declarasse não haver indicações desses alunos em suas classes, foi possível detectar nos relatos dos três âmbitos, transcritos e comentados anteriormente, indícios da presença dos mesmos.

Então, considerando-se o percentual estabelecido na literatura especializada de que há ocorrência de 1\% a 10\% (METTRAU, 2000) dessas pessoas em qualquer grupamento, nota-se que no contingente discente dessa instituição existem alunos com altas habilidades ainda desassistidos.

Essa é uma realidade já evidenciada em outras investigações da área há algum tempo e que continua mantendo-se, apesar do aprimoramento das leis e do incentivo e apoio de órgãos oficiais para a implantação e implementação de ações que possam minimizar tal demanda como por exemplo a Lei N 9.394/96 Diretrizes e Bases da Educação Nacional. A Portaria No 1.793/1994 que recomenda a complementação dos currículos de formação de docentes e outros profissionais que interagem com pessoas com necessidades educativas especiais. O Decreto $\mathrm{N}^{\circ}$ $6.571 / 2008$ que dispões sobre o atendimento educacional especializado às pessoas com necessidades espaciais, dentre outros. 


\section{CONSIDERAÇÕES FINAIS}

As leis são claras quanto ao efetivo atendimento dessa clientela nos diferentes âmbitos e níveis educacionais (LDB No 9.394/96, Capítulo V, Artigos 58, 59 e 60). É uma determinação a ser cumprida, não uma opção de qual clientela ou necessidade atender, mesmo sendo essa uma tarefa árdua e complexa.

Nesse sentido vale ressaltar ainda a iniciativa da Secretaria de Educação Especial do Ministério da Educação de implantar "em parceria com as Secretarias de Educação em todas as Unidades da Federação, os Núcleos de Atividades de Altas Habilidades / Superdotação (NAAH/S). O projeto disponibiliza recursos didáticos-pedagógicos e formação de profissionais especializados para atendimento aos desafios acadêmicos e sócio-emocionais" e também motivacionais dos alunos com esse perfil. Além disso, visa proporcionar suporte às instituições educacionais que se interessem em atendê-los (BRASIL, 2006). Em 2007, dá continuidade ao atendimento especializado a essa clientela subsidiando ações nessa área específica, com a elaboração do conjunto de quatro volumes de livros didático-pedagógicos "Encorajando Potenciais" com orientações práticas para o professor e a família (BRASIL, 2007).

Ficou também evidente a importância e premência em se reformular os cursos de formação de professores incluindo disciplinas que tratem das altas habilidades, no intuito de qualificar melhor os docentes, sanando ou pelo menos reduzindo, sua dificuldades nessa especialidade. .Concomitantemente, as escolas podem promover periodicamente, Centro de Estudos e outros momentos que incluam o estudo do tema nos debates pedagógicos.

É orientação legal, a formalização do registro no histórico escolar do aluno de quaisquer indicações feitas pelo professor, ou demais profissionais e setores das escolas onde o aluno tenha estudado ao longo da sua trajetória educacional, mesmo que a instituição não desenvolva ações de atendimento imediato. Este é um direito e um dever da escola. A realização desse procedimento possibilitará a veiculação das informações referentes à vida escolar do aluno no âmbito escolar onde ele estiver inserido. Dessa forma, garantir-se-á minimamente a solicitação dos respondentes dessa investigação em conhecer a história do seu aluno. Assim, poderão melhor compreender as suas atitudes, apoiar o seu desenvolvimento e desempenho além de orientar a busca de conhecimentos e estratégias individuais e / ou conjuntas mais adequadas à condução do trabalho didático-pedagógico, direcionado à potencialização das suas capacidades e habilidades, nas diversas áreas.

Ressalte-se também que esses cuidados são geralmente praticados no cotidiano das escolas, quando da indicação, acompanhamento e orientação de alunos com outros tipos de especificidades (por exemplo, déficit visual, auditivo, síndromes, transtornos etc.).

O entrosamento família-escola é imprescindível porque favorece trocas valiosas de informações sobre o estudante (seus gostos, interesses, dificuldades 
etc.) que irão ajudar na condução de estratégias alternativas no cotidiano escolar. Será de grande valia na resolução de possíveis situações ou problemas passados, presentes ou futuros no grupo social. Em geral, e numa perspectiva otimista, proporcionará que a família, uma vez informada, busque suporte fora da escola e amplie suas ações para o enriquecimento acadêmico-sócio-cultural do aluno.

A circulação de informações sobre as altas habilidades no campo educacional é fundamental. Esse embasamento não se deve restringir apenas ao conceito e características marcantes, mas deve-se ampliar para a viabilização de subsídios sobre a prática educacional relativa ao processo ensino-aprendizagem, elaboração de programas, planejamento de atividades, dentre outras. Isso porque segundo os estudiosos da área, as pessoas com altas habilidades demandam ações criativas e de pesquisas que envolvem alta qualidade e aprofundamento por parte de toda equipe pedagógica e portanto beneficiará a todos os alunos. Essas ações irão contribuir, certamente, para o crescimento acadêmico, motivacional e criativo do grupo de pertencimento do estudante, em princípio, ampliando-se para toda a comunidade escolar. Portanto, investir em ações educativas para as pessoas com altas habilidades, é implementar educação de qualidade e desenvolvimento para todos no seu entorno.

No entanto, abre-se uma lacuna frente a questões que mereceriam maiores esclarecimentos e que foram geradas a partir dessa investigação e talvez possam ser temáticas para próximos estudos. Por que os professores não formalizaram a indicação desses alunos junto aos Setores (SESOPs e SEE) responsáveis? Por que os Setores (SESOPs e SEE) responsáveis por essas ações, não formalizaram as indicações, suspeitas e/ ou comentários dos professores, uma vez que, segundo nossos resultados, conheciam a legislação? Onde estão os alunos com indicadores de altas habilidades/superdotação oriundos de outras instituições e já percebidos pelos professores?

Finalizando, ressalta-se que não se pretende generalizar os resultados encontrados nessa investigação. Mas entende-se que os mesmos sejam importantes como ponto de referência no planejamento de outras investigações além de também, ser pré-requisito para implementar ações no âmbito educacional em geral e nessa escola em particular.

Destaca-se, portanto, a importância de se introduzir e ampliar o acervo de informações sobre as altas habilidades nas escolas e nas universidades.

Finalmente, não se pode deixar de refletir sobre a contribuição social desse estudo, multifacetado e delicado, mas instigante e desafiador por se tratar de um problema real e ainda sem amplas soluções. 


\section{REFERÊNCIAS}

BARDIN, L. Análise de conteúdo. 3. ed. Lisboa: Editora 70, 2007.

BENITO MATE, Y. et al. Intervención e investigación psicoeducativas en alumnos superdotados. Salamanca:Amarú Ediciones, 1994.

. Inteligencia y algunos factores de personalidade em superdotados. Salamanca: Amarú Ediciones, 1996.

BRASIL. MINISTÉRIO DA EDUCAÇÃO E CULTURA. Portaria No 1.793 de dezembro de 1994. Recomenda a complementação de currículos de formação de docentes e outros profissionais da Educação Especial. Disponível em: <http://portal.mec.gov.br/seesp/ arquivos/pdf/port1793.pdf>. Acesso em: 25 jul. 2011.

BRASIL. MINISTÉRIO DA EDUCAÇÃO E CULTURA. Lei No 9.394 Diretrizes e Bases da Educação Nacional. Brasília: Editora do Brasil, 1996.

BRASIL. MINISTÉRIO DA EDUCAÇÃO E CULTURA. SECRETARIA DE EDUCAÇÃO ESPECIAL. Documento orientador execução da ação dos núcleos de atividades de altas habilidades / superdotação. Brasília: MEC, 2006.

BRASIL. MINISTÉRIO DA EDUCAÇÃO E CULTURA. SECRETARIA DE EDUCAÇÃO ESPECIAL. Altas habilidades/superdotação encorajando potenciais. Brasília: MEC, 2007.

BRASIL. MINISTÉRIO DA EDUCAÇÃO E CULTURA. Decreto No 6.571 de 17 de setembro de 2008. Dispõe sobre o atendimento especializado aos Portadores de Necessidades Especiais, Disponível em: <http:/ / portal.mec.gov.br/dmdocuments/ parecer_CEB_132009.pdf>. Acesso em: 25 jul. 2011.

FAZENDA, I. C. A. Interdisciplinaridade: um projeto em parceria. 3. ed. São Paulo: Edições Loyola, 1995.

LANDAU, E. A coragem de ser superdotado. São Paulo: Arte \& Ciência Editora, 2002.

METTRAU, M. B. Inteligência patrimônio social. Rio de Janeiro: Qualitymark Editora Ltda, 2000 .

. Educação moral, inteligência e altas habilidades. In: BARRETO, M. S. L.; METTRAU, M. B. (Org.). Rumos e Resíduos da Moral Contemporânea. Niterói: Muiraquitã, 2007. p.128-147.

RENZULLI, J. S. El Concepto de los Tres Anillos de la Superdotacion: um modelo de desarrollo para uma productividad creativa. In: BENITO MATE, Y. (Coord.). Intervención e Investigación Psicoeducativas en Alumnos Superdotados. Salamanca: Amarú Ediciones, 1994. p. 41-78

. O que é esta coisa chamada superdotação, e como a desenvolvemos? Uma retrospectiva de vinte e cinco anos. Educação. Revista eletrônica da Pontifícia Universidade Católica do Rio Grande do Sul:, Porto Alegre, 2004. Disponível em: <http//www.revistaseletronicas. pucr/ojs/index.php/faced/article/viewFile/375/272>. Acesso em: 19 jul. 2011.

RICHARDSON, R. J. Pesquisa social métodos e técnicas. 3. ed. São Paulo: Editora Atlas S.A, 2008. 
BARRETO, C. M. P. F.; METTRAU, M. B.

SPINK, M. J. O Conhecimento no cotidiano as representações sociais na perspectiva da psicologia social. 1. ed. São Paulo: Editora Brasiliense, 1993.

WINNER, E. Crianças superdotadas: mitos e realidades. Porto Alegre: Artes Médicas, 1998.

Recebido em: 14/02/2011

Reformulado em: 10/08/2011

Aprovado em: 12/11/2011 